\title{
Análise da percepção ambiental da população de Maceió/AL com relação à logística reversa de resíduos eletroeletrônicos
}

\begin{abstract}
A acelerada obsolescência dos equipamentos eletroeletrônicos tem se destacado como um problema ambiental cada vez mais significativo, uma vez que gera a necessidade de descarte adequado destes produtos conforme preconizam os procedimentos da cadeia de logística reversa para reaproveitamento no ciclo produtivo. A logística reversa tem sido alvo de políticas públicas nos âmbitos estadual e municipal e, no caso do estado de Alagoas, o contexto atual é marcado pela formulação e consolidação de legislações e planos ambientais para o descarte de resíduos eletroeletrônicos em consonância com a política nacional. O objetivo deste estudo foi analisar a percepção ambiental da população do município de Maceió/AL em relação à logística reversa dos resíduos eletroeletrônicos. No seu proceder metodológico, a pesquisa combinou um levantamento quantitativo tipo survey contando com 357 respondentes, para mensurar a problemática dos resíduos eletroeletrônicos, confrontando-o com uma análise qualitativa, a partir da visão do gestor de uma das empresas com licença ambiental para destinação desses resíduos. Os principais resultados apontaram que o aparelho celular foi o equipamento mais adquirido $(91,27 \%)$ e, consequentemente, o mais descartado (43,38\%) pelos respondentes; um número considerável de pessoas ainda não tem o hábito de descartar o resíduo eletrônico (32,68\%); 48,60\% dos respondentes alegaram conhecer parcialmente o termo lixo eletrônico, mas não sabem do que se trata; após a compra de um novo equipamento, $40,28 \%$ declararam realizar doação do antigo e $67,70 \%$ afirmaram desconhecer a existência dos pontos de coleta para descarte. No entanto, na visão do gestor entrevistado, o grau de conscientização da população vem aumentando em consonância com a demanda para coleta de resíduos pela empresa. Fo possivel concluir que a estrutura ainda incipiente da cadeia reversa de eletroeletrônicos no município propicia um cenário de descarte aleatório e inadequado, contrariando o que determinam os dispositivos ambientais legais vigentes no próprio município desde 2015
\end{abstract}

Palavras-chave: Sustentabilidade; Logística reversa; Resíduos eletroeletrônicos.

\section{Analysis of the environmental perception of the population of Maceió/AL in relation to the reverse logistics of electronic waste}

\begin{abstract}
An accelerated electronic equipment obsolescence has emerged as an increasingly significant environmental problem, since it generates the need for proper disposal as recommended by the reverse logistics chain procedures for reuse in the production cycle. Reverse logistics has been the target of public policies at different government levels. In Alagoas State, Brazil, the current context is marked by the formulation and consolidation of e-waste laws and plans for disposal of electronic products according to national policy. This research aimed to analyze the electronic waste reverse logistics based on population's environmental perception in Maceió City, Brazil. In its research design, the study combined a survey with 357 respondents to measure electronic waste reverse logistics based on population's environmental perception in Maceió City, Brazil. In its research design, the study combined a survey with 357 respondents to measure
the electronic waste problem, confronting it with an environmental-licensed company manager's perspective. The main results showed that smartphones was the most purchased equipment (91.27\%) and, consequently, the most discarded (43.38\%); a considerable number of people are not yet in the habit of discarding electronic waste (32.68\%); $48.60 \%$ claimed to partially know the electronic waste term, but do not know what it is about; after purchasing new equipment, $40.28 \%$ declared donating the old one and $67.70 \%$ said they were unaware of municipa recyclable e-waste collectors existence. However, in the interviewed manager's perspective, the population's level of awareness has been increasing in line with the demand for waste collection by your company. It was possible to conclude that the still incipient structure of municipal electronics reverse chain provides a random and inadequate disposal scenario for population, on the contrary to what determines the legal e-waste municipal provisions in force since 2015 .
\end{abstract}

Keywords: Sustainability; Reverse logistic; Electronic waste.

Topic: Logística Reversa

Reviewed anonymously in the process of blind peer.
Received: 10/05/2020

Approved: 02/06/2020
Marcílio Ferreira de Souza Júnior (iD

Universidade Federal Rural de Pernambuco, Brasi

http://lattes.cnpq.br/2702843581642246

http://orcid.org/0000-0003-0237-392X

marcilio.souzajr@ufrpe.br

Mônica Ximenes Carneiro da Cunha (iD)

Instituto Federal de Alagoas, Brasil

http://lattes.cnpq.br/1775024859845111

http://orcid.org/0000-0002-5869-9358

mxcc@hotmail.com

Katty Pollyanni Ferreira Silveira (id

Instituto Federal de Alagoas, Brasil

http://lattes.cnpq.br/0050939354078708

http://orcid.org/0000-0002-9158-7972

kattysilveira@live.com

d

DOI: 10.6008/CBPC2179-6858.2020.004.0022

\author{
Francisco Vital Silva Júnior (it \\ Instituto Federal de Alagoas, Brasil \\ http://lattes.cnpq.br/1514136586550136 \\ http://orcid.org/0000-0002-4269-5870 \\ fcojunior3@gmail.com \\ Márcio Azevedo Rocha \\ Instituto Federal de Alagoas, Brasil \\ http://lattes.cnpq.br/9608720181990103 \\ http://orcid.org/0000-0001-9300-8076 \\ mazevedo.al@gmail.com \\ Tadeu Patêlo Barbosa (iD) \\ Instituto Federal de Alagoas, Brasil \\ http://lattes.cnpq.br/2064848946042706 \\ http://orcid.org/0000-0002-7688-6093 \\ tadeupbarbosa@gmail.com
}

\section{Referencing this:}

SOUZA JÚNIOR, M., F.; CUNHA, M. X. C.; SILVEIRA, K. P. F.; SILVA JÚNIOR, F. V.; ROCHA, M. A.; BARBOSA, T. P.. Análise da percepção ambiental da população de Maceió/AL com relação à logística reversa de resíduos eletroeletrônicos. Revista Ibero-Americana de Ciências Ambientais, v.11, n.4, p.255-269, 2020. DOI:

http://doi.org/10.6008/CBPC2179-6858.2020.004.0022 


\section{INTRODUÇÃO}

A acelerada obsolescência dos equipamentos eletroeletrônicos tem se destacado como um problema ambiental cada vez mais significativo, tanto em países desenvolvidos quanto em desenvolvimento, pois o descarte destes materiais representa o tipo de resíduo sólido que mais cresce no mundo, devido ao consumo desenfreado de itens como celulares, notebooks, tablets e similares, cada vez mais de uso pessoal e não coletivo (OLIVEIRA et al., 2012; SANT'ANNA et al., 2015; DEMAJOROVIC et al., 2016). Tudo isso resulta em aumento no descarte de produtos que possuem, em sua composição, elementos químicos tóxicos, como chumbo, cádmio, mercúrio, que causam contaminação do solo, da água e podem trazer danos à saúde.

Cardozo et al. (2015) ressaltaram que o descarte incorreto destes materiais influencia diretamente na qualidade de vida da população. Além disso, as consequências dos problemas ambientais não atingem a população de forma proporcional, uma vez que, em geral, os menos privilegiados é que acabam se instalando próximos a locais degradados ou que recebem inadequadamente os resíduos sólidos. Desta forma, enfrentar os problemas ambientais envolve abordar o desenvolvimento sustentável de forma ampla, observando as múltiplas realidades, de forma a promover ao máximo o meio em que se vive. Isso exige uma adequada gestão de resíduos sólidos, a fim de minimizar os impactos negativos ao meio ambiente e maximizar o ciclo de vida útil dos diversos materiais capazes de se renovarem e retornarem ao ciclo produtivo (FROTA et al., 2016).

Ademais, as dimensões territoriais do Brasil, bem como os diferentes aspectos regionais, especialmente no que se refere à educação, cultura e consciência ambiental, impactaram na definição de procedimentos operacionais e de especificações mínimas a serem adotados nos serviços públicos de limpeza urbana e de manejo dos resíduos sólidos, incluindo o descarte final ambientalmente adequado de resíduos eletroeletrônicos, resultando na formulação da Política Nacional de Resíduos Sólidos (PNRS) (BRASIL, 2010).

A PNRS classifica os resíduos conforme a sua fonte geradora, sendo os principais: domiciliares, industriais, serviços de saúde, construção civil e mineração. Ainda no referido plano consta a descrição do manejo dos resíduos com logística reversa, sendo que nesta categoria engloba a classe dos resíduos eletroeletrônicos (REEs) e seus componentes de uso doméstico, cuja regulamentação foi instituída apenas em 2020 (BRASIL, 2020).

Cabe ressaltar que a geração dos REEs é de complexa caracterização, por ser dinâmica no tempo e também por estar intrinsecamente relacionada a diversos fatores, como nível de escolaridade, desenvolvimento tecnológico, economia, políticas governamentais, estratégias da indústria para a comercialização e comportamento dos usuários em relação à substituição e manutenção dos equipamentos (RODRIGUES, 2012).

A logística reversa é um instrumento da PNRS que contempla um conjunto de procedimentos, ações e meios destinados a viabilizar a coleta e a restituição dos resíduos sólidos para reaproveitamento do setor empresarial em seu ciclo produtivo (BRASIL, 2010). De fato, a PNRS representa uma abordagem inovadora entre países em desenvolvimento no que se refere a implementação da logística reversa de REEs. Produtores, 
importadores e empresas de varejo passaram a ser corresponsáveis pelo desenvolvimento e implementação de um modelo de logística reversa, independente do sistema de gestão de resíduos públicos (DEMAJOROVIC et al., 2016). A lei brasileira também é a primeira regulamentação mundial a reconhecer a importância das organizações de catadores nos fluxos reversos de REE e estimular a integração destes trabalhadores nos futuros programas de logística reversa (DEMAJOROVIC et al., 2013).

A logística reversa também tem sido alvo de políticas públicas nos âmbitos estadual e municipal (FROTA et al., 2016). No caso do estado de Alagoas, o contexto atual é marcado pelo quadro deficitário em relação à organização e prestação de serviços de manejo dos resíduos sólidos, porém, com perspectiva de mudanças, uma vez que houve a formação dos consórcios regionais de resíduos, além da elaboração do Plano de Estadual de Resíduos Sólidos (PERS) e dos Planos Intermunicipais de Resíduos Sólidos, com objetivo de melhorar o cenário atual do saneamento ambiental e gerenciamento de resíduos sólidos no estado (ALAGOAS, 2016). Decerto, o levantamento da situação dos resíduos sólidos é fundamental para o planejamento da gestão integrada desses resíduos junto aos municípios, permitindo, assim, que sejam traçadas estratégias para a realização de ações de redução, reciclagem, reaproveitamento, coleta, transporte, tratamento e destinação adequada desses resíduos (MACEIÓ, 2017).

De acordo com o último censo do Instituto Brasileiro de Geografia e Estatística ${ }^{1}$, Maceió é o principal centro urbano alagoano, concentrando o maior contingente populacional do estado, com uma população de 932.748 habitantes. Estima-se, no PERS de Alagoas, que o estado todo produz cerca de 2.022,08 toneladas de resíduos sólidos urbanos diariamente, sendo que $62,49 \%$ são gerados pela população residente na Região Metropolitana em função do porte da capital Maceió, principalmente pela influência da atividade hoteleira e destinação dos resíduos produzidos pelos meios de hospedagens (MOURA et al., 2019). Percebe-se que Maceió é o único município do estado com produção de resíduos urbanos acima de 1.000 toneladas diárias, caracterizando-o como o principal gerador destes resíduos. No que tange aos REEs, cabe, atualmente, a apenas duas empresas licenciadas no município, o tratamento desses resíduos, que equivalem a aproximadamente $7.000 \mathrm{~kg}$ por mês, sendo encaminhados para as indústrias habilitadas fora do estado (ALAGOAS, 2016).

Sendo assim, o Plano Municipal de Gestão Integrada de Resíduos Sólidos (PMGIRS) de Maceió (MACEIÓ, 2017) se constituiu em uma ferramenta para alcançar a universalização dos serviços ambientais, o que levou ao posterior marco da gestão de resíduos na capital com a atualização e instituição do novo Código Municipal de Limpeza Urbana (MACEIÓ, 2019), visto que adequou oficialmente a gestão dos resíduos à política nacional. Com relação especificamente à problemática dos REEs, já em 2015, o município sancionou a Lei № 6496/2015, que dispôs sobre o gerenciamento, coleta, reutilização, reciclagem e destinação final do lixo tecnológico. De acordo com o disposto nesta lei, "os produtos descartados e resíduos tecnológicos deverão ser coletados, reutilizados, reciclados e receber tratamento final específico e ambientalmente adequado pelas empresas que fabricam e produzem, importam, distribuem e comercializam esses

${ }^{1}$ https://cidades.ibge.gov.br/brasil/al/maceio/panorama 
equipamentos ou seus componentes" (MACEIÓ, 2015).

No entanto, de nada adiantaria existir uma lei, se não houvesse educação ambiental, desde as escolas, para conscientizar a população a respeito. O estudo realizado por Silva et al. (2018), com estudantes de uma escola pública de Maceió/AL, revelou a preocupação dos jovens com a preservação do meio ambiente e o senso de responsabilidade com o próprio lixo produzido e com o reaproveitamento do mesmo, sinalizando que a população reconhece a importância de realizar a seleção dos resíduos sólidos e as consequências que o gerenciamento inadequado da mesma causa ao meio ambiente. Há, portanto, uma clara percepção em relação aos problemas ambientais atuais e a conscientização para reciclagem dos lixos produzidos por esta parcela da população.

Os estudos que se baseiam na percepção ambiental a definem como uma tomada de consciência das problemáticas ligadas ao ambiente, ou seja, ao ato de perceber o ambiente em que se está inserido. A percepção implica em interpretação, sendo, portanto, um processo de organização das sensações recebidas para que a consciência e a relação com o ambiente se desenvolva. Esta relação, por sua vez, se manifesta por meio de ações, cujas normas que as regem são pautadas pelas diferenças culturais que influenciam a interpretação de cada sujeito em relação ao meio ambiente (RODRIGUES et al., 2012).

Ainda sob a ótica da percepção ambiental, contextualizada na população de Maceió/AL, Melo e Lima (2020) ressaltaram a relevância do papel de uma cooperativa perante a sociedade por meio de campanhas de destinação, descarte consciente e reciclagem de parte dos resíduos sólidos, com vistas a reduzir a quantidade de rejeitos encaminhados para disposição final ambientalmente adequada. Silva et al. (2020), por sua vez, estimaram as características dos resíduos gerados e destinados ao aterro municipal de Maceió/AL, quantificando e classificando-os como orgânicos, recicláveis e rejeitos. Os dados revelaram que os resíduos orgânicos representam $67,45 \%$, os materiais potencialmente recicláveis $20,32 \%$, e os rejeitos representam $12,23 \%$ de todos os resíduos do município. O que reforça a importância de uma logística adequada para o gerenciamento e destinação destes resíduos.

Nesse contexto, o objetivo deste estudo foi analisar a percepção ambiental da população do município de Maceió/AL em relação à logística reversa dos resíduos eletroeletrônicos. Para tanto, no seu proceder metodológico, a pesquisa combinou um levantamento quantitativo tipo survey para aferir a opinião dos respondentes sobre o assunto em tela, confrontando-a com uma análise qualitativa a partir da visão de uma das empresas licenciadas pela Prefeitura na destinação de REEs no município.

O artigo está organizado da seguinte forma: a seção 2 apresenta uma breve revisão de literatura sobre logística reversa de resíduos eletroeletrônicos; a seção 3, por sua vez, descreve o procedimento metodológico adotado na pesquisa; a seção 4 exibe os resultados obtidos com as etapas qualitativa e quantitativa da pesquisa, com as respectivas confrontações; por fim, a seção 5 apresenta as conclusões do presente estudo e sugestões para trabalhos futuros. 


\section{REVISÃO TEÓRICA}

\section{Logística reversa de resíduos eletroeletrônicos}

De acordo com a visão estabelecida na PNRS (BRASIL, 2010), os resíduos sólidos são os materiais passíveis de aproveitamento, enquanto os rejeitos são materiais que devem ser enviados para a destinação final depois de esgotadas todas as possibilidades de tratamento, recuperação ou reaproveitamento. Dentro da categoria de resíduos sólidos, existem os resíduos eletroeletrônicos (REEs), que abrangem o lixo derivado de equipamentos eletrônicos (e-lixo), incluindo computadores e seus componentes e periféricos, bem como os eletrodomésticos. Tais resíduos, quando descartados indevidamente, constituem-se em um sério risco para o meio ambiente, uma vez que são compostos por metais pesados e tóxicos, como mercúrio, cádmio, berílio e chumbo. Estes materiais podem contaminar o lençol freático, quando em contato com o solo, ou o ar, quando queimados, além de afetar a saúde dos catadores em lixões (NATUME et al., 2011).

Os REEs têm recebido atenção exatamente por apresentarem substâncias potencialmente perigosas e pelo aumento em sua geração no país ao longo das últimas décadas, consequência dos avanços tecnológicos, aumento do mercado de consumo, redução da vida útil dos produtos eletrônicos que resultam na elevação na taxa de descarte (GUNTHER, 2008). Após o uso, estes produtos se tornam inservíveis para o consumidor e passam a ser considerados resíduos, devendo haver uma logística no sentido contrário, de forma que o fluxo destes resíduos seja do consumidor ao fabricante, que promoverá o aproveitamento no ciclo produtivo industrial, reciclagem ou tratamento final (ALAGOAS, 2016).

Foi a partir do estabelecimento da PNRS que se tornou obrigatória a estruturação e implementação de sistemas de logística reversa, mediante retorno dos produtos após o uso pelo consumidor, de forma independente do serviço público de limpeza urbana, aos fabricantes, importadores, distribuidores e comerciantes, sendo incluídos na cadeia os seguintes resíduos: pneus; pilhas e baterias; lâmpadas fluorescentes; produtos eletroeletrônicos e seus componentes; agrotóxicos; e óleos lubrificantes (BRASIL, 2010; ALAGOAS, 2016). Portanto, trata-se de um fluxo ou movimento de produtos, materiais e embalagens na direção oposta à tradicional, com o objetivo de criar ou recapturar valor ou de descartá-los corretamente (TIBBEN-LEMBKE et al., 2002).

A logística reversa é um dos instrumentos para aplicação da responsabilidade compartilhada pelo ciclo de vida dos produtos. A PNRS define a logística reversa como um "instrumento de desenvolvimento econômico e social caracterizado por um conjunto de ações, procedimentos e meios destinados a viabilizar a coleta e a restituição dos resíduos sólidos ao setor empresarial, para reaproveitamento, em seu ciclo ou em outros ciclos produtivos, ou outra destinação final ambientalmente adequada" (BRASIL, 2010).

Sant'Anna et al. (2015) explicaram que, para a aplicação dessa logística, a lei aponta instrumentos jurídicos contratuais como os acordos setoriais e os termos de compromisso a serem realizados entre poder público e setor empresarial e afirmaram que, apesar de ainda incipiente e em processo de consolidação, a política de implantação da logística reversa dos eletroeletrônicos tem avançado no Brasil.

No município que o presente estudo realizou a investigação, conforme explanado anteriormente, foi 
instituída a Lei Municipal № 6496/2015 que determinou que os fabricantes, importadores, distribuidores e comerciantes de produtos tecnológicos devem disponibilizar recipientes de coleta para REE, devidamente sinalizados, nos próprios locais de comercialização ou ainda, de grande fluxo de pessoas. Também foi definido que as empresas responsáveis ou contratadas para destinação final dos produtos e componentes eletroeletrônicos poderão criar parcerias para a realização de qualquer parte do gerenciamento (coleta seletiva, reutilização, reciclagem e deposição final de produtos tecnológicos) com qualquer Associação ambiental vigente no município (MACEIÓ, 2015).

De acordo com Leite (2009) a logística reversa controla o fluxo da volta dos bens de pós-consumo e pós-venda ao ciclo produtivo, por diversos meios reversos, associando valores de diferentes naturezas: ecológico, econômico, logístico, de prestação de serviços, dentre outros. Em suma, com essa proposta, a empresa não apenas tem a responsabilidade de fazer chegar o produto ao consumidor, que seria a logística direta, mas também se compromete a gerenciar todo o ciclo de retorno de rejeitos, culminando com o adequado descarte e retorno de insumos (como componentes e embalagens) à indústria. Cabe ressaltar que, no caso dos REEs, as informações sobre a destinação do equipamento quando obsoleto devem vir explicitadas no manual do produto, que frequentemente não é lido pelo consumidor, e este, por sua vez, acaba não entendendo o potencial tóxico dos componentes, a importância do descarte adequado, bem como a possibilidade de fazê-lo via empresas responsáveis por este relacionamento com o fabricante.

\section{METODOLOGIA}

A presente pesquisa classifica-se como descritiva e exploratória, combinando métodos quantitativo e qualitativo (CRESWELL, 2009) de coleta de dados no seu desenho metodológico (figura 2). O desenho da pesquisa busca ilustrar, de forma sequencial, os passos para a sua operacionalização.

\begin{tabular}{|c|c|}
\hline \multicolumn{2}{|c|}{ Objetivo da pesquisa } \\
\hline \multicolumn{2}{|c|}{$\begin{array}{l}\text { Analisar a percepção da população em relação à logística reversa dos } \\
\text { resíduos eletroeletrônicos na cidade de Maceió/AL. }\end{array}$} \\
\hline \multicolumn{2}{|c|}{ Natureza da pesquisa } \\
\hline \multicolumn{2}{|c|}{ Pesquisa descritiva, exploratória, quali-quantitativa. } \\
\hline \multicolumn{2}{|c|}{ Estratégias de coleta dos dados } \\
\hline Etapa Quantitativa & Etapa Qualitativa \\
\hline $\begin{array}{l}\text { Survey a partir de questionário } \\
\text { fechado online }\end{array}$ & $\begin{array}{c}\text { Entrevistas semiestruturadas com } \\
\text { o gestor de uma empresa } \\
\text { licenciada para coleta de resíduos } \\
\text { eletrônicos }\end{array}$ \\
\hline Análise quanti-quali & iva dos dados coletados \\
\hline
\end{tabular}

Figura 2: Desenho da pesquisa.

O delineamento das estratégias de coleta de dados da pesquisa envolveu uma etapa quantitativa, que adotou o levantamento tipo survey para obtenção dos dados sobre as opiniões de uma população-alvo, que foram pessoas residentes em Maceió/AL. Esta estratégia utilizou-se de uma amostra calculada para 
englobar um segmento ou parcela da população e, a partir disso, estimar as reais características da população representada (COOPER et al., 2003).

O survey foi operacionalizado através de um questionário com 11 (onze) perguntas fechadas, com proposições dicotômicas, tricotômicas e de múltipla escolha, sendo aplicados nos meses de agosto e setembro de 2018, com suporte da plataforma SurveyMonkey. A amostra foi composta por 357 (trezentos e cinquenta e sete) respondentes, sendo a população escolhida de forma aleatória, utilizando a técnica de snowballing (LEEUW et al., 2008), a partir dos contatos pessoais de cada pesquisador, solicitando que os mesmos compartilhassem com suas redes de contato, aumentando o número de respondentes.

O instrumento de coleta de dados aplicado à população referiu-se aos seguintes aspectos: grau de instrução e faixa etária dos respondentes; quais os equipamentos eletroeletrônicos adquiridos e descartados nos últimos 05 (cinco) anos; o nível de conhecimento sobre resíduos eletroeletrônicos; critérios de descarte dos equipamentos que possuíam e para onde eram encaminhados; nível de conhecimento acerca dos procedimentos de descarte dos REEs, incluindo postos de coleta, e se já tinham recebido alguma informação a respeito; o interesse pela leitura do manual de instruções ao adquirir um novo equipamento; e, por fim, qual a opinião dos respondentes sobre a responsabilização pelo descarte de equipamentos eletroeletrônicos. Foi utilizada estatística descritiva para análise dos dados.

O segundo movimento no campo, que foi a etapa qualitativa da pesquisa, envolveu visitas in loco para a realização de 02 (duas) entrevistas semiestruturadas com o gestor de uma empresa pioneira na coleta e destinação adequada dos resíduos eletroeletrônicos, que desde 2013 atua com licença ambiental concedida pela Prefeitura de Maceió. $\mathrm{O}$ intuito desta etapa foi confrontar os dados obtidos dos questionários com a visão do referido gestor sobre a problemática da coleta e destinação de REEs.

\section{RESULTADOS E DISCUSSÃO}

Nesta seção são apresentados os resultados da coleta de dados realizada no campo, bem como as suas respectivas análises, seguindo as etapas previstas no desenho da pesquisa descrito anteriormente.

\section{Etapa quantitativa: Percepção da população com relação à logística reversa de resíduos eletroeletrônicos no município de Maceió/AL}

As duas primeiras perguntas do questionário abordaram aspectos referentes à caracterização da amostra. Com relação à faixa etária, a pesquisa contou com $23,10 \%$ dos respondentes com idade entre 15 e 25 anos; $26,76 \%$ entre 36 e 35 anos; $26,76 \%$ entre 36 e 45 anos e $23,38 \%$ acima de 46 anos, ou seja, bastante balanceada. Por sua vez, no que se refere ao nível de escolaridade dos respondentes, predominou pessoas com pós-graduação $(29,66 \%)$, seguido de superior incompleto $(24,01 \%)$ e completo $(19,77 \%)$, o que reflete uma amostra composta por mais de $70 \%$ de pessoas com bom nível de instrução.

De acordo com os dados obtidos na pesquisa, 91,27\% assinalaram o smartphone como o equipamento eletroeletrônico mais adquirido nos últimos 5 anos, seguido do notebook (63,94\%). Esses 
dados vão ao encontro dos resultados obtidos em pesquisa recente da Fundação Getúlio Vargas (FGV)², que colocou o Brasil entre os países que apresentaram um crescente aumento nas vendas desses produtos, com consequente potencial de geração de descarte de resíduos, fato este que foi constatado pelos modelos matemáticos de estimativa de Franco et al. (2011) e Araújo et al. (2012).

Consequentemente, conforme apresentado no gráfico 1, o aparelho celular foi o equipamento assinalado como o mais descartado, por 43,38\% dos respondentes. Esse comportamento pode ser explicado por dois fatores. O primeiro é que hoje as pessoas buscam substituir, com certa frequência, os seus equipamentos por outros mais modernos, tornando o celular quase que um objeto de uso descartável. 0 segundo é a questão da obsolescência programada, pois hoje em dia os produtos são feitos para terem uma durabilidade menor, diferente de produtos feitos há 15 ou 20 anos atrás, que eram produzidos com uma vida útil maior, já que o poder aquisitivo da população naquela época não permitia a troca de produtos eletrônicos de forma tão rápida como o praticado nos dias de hoje.

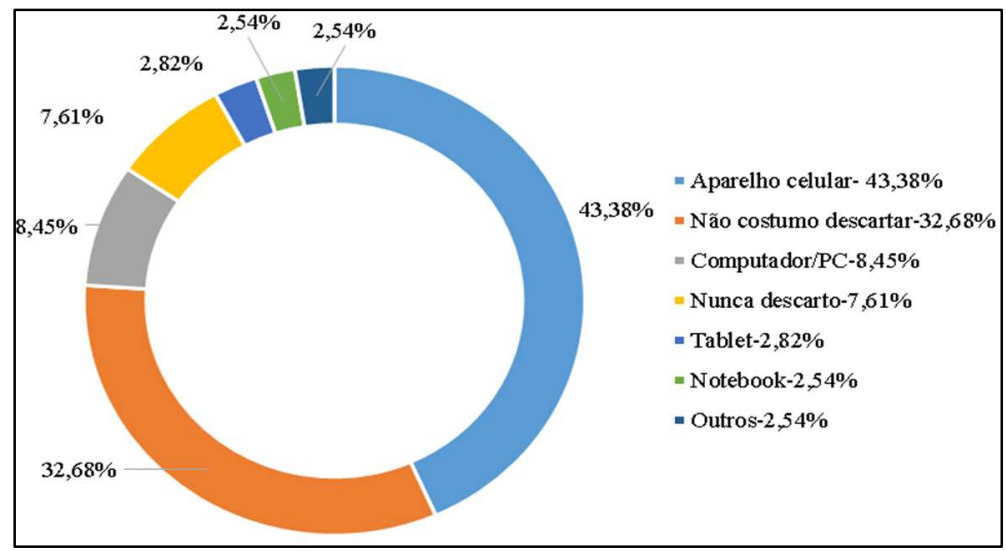

Gráfico 1: Situação de descarte dos eletroeletrônicos nos últimos 5 (cinco) anos.

A pesquisa revelou também um número considerável de pessoas que não costumam descartar o resíduo eletrônico (32,68\%), mesmo apresentando elevado nível de escolaridade, deixando o alerta sobre a necessidade de divulgação e orientação da população acerca do descarte adequado desse tipo de lixo. Nesse sentido, Sachuck et al. (2008) apontaram que discussões abordando os problemas ambientais, a conservação dos recursos naturais, o aquecimento global, a economia de energia e a sustentabilidade vêm sendo alvo de interesse de gestores de empresas produtoras de tecnologia para sensibilização dos usuários sobre os impactos desses resíduos no meio ambiente.

Em relação ao nível de conhecimento sobre o lixo eletrônico (e-lixo), o gráfico 2 revela que 8,71\% dos respondentes afirmaram não possuir nenhum conhecimento sobre o tema e 48,60\% conhecem parcialmente, mas não sabem do que se trata. De fato, o termo ainda confunde a população com 'lixo eletrônico' de caixa de e-mail. Estes dados sinalizam para a necessidade de ampliar a divulgação acerca do tema, das mais diversas formas, especialmente nas escolas.

Conforme ilustrado no gráfico 3, ao serem questionados sobre os motivos do descarte dos produtos eletroeletrônicos, as alternativas 'defeito' e 'fim da vida útil' foram apontadas como as principais para o 
descarte, ambas com 36,69\%. 18,21\% dos entrevistados não descartaram seus equipamentos, permanecendo com os mesmos guardados em casa. 5,32\% assinalam os novos modelos como motivo do descarte dos antigos. Já 2,24\% relataram que as funções adicionais dos equipamentos mais novos são mais atrativas e $0,84 \%$ indicaram outros motivos não especificados.

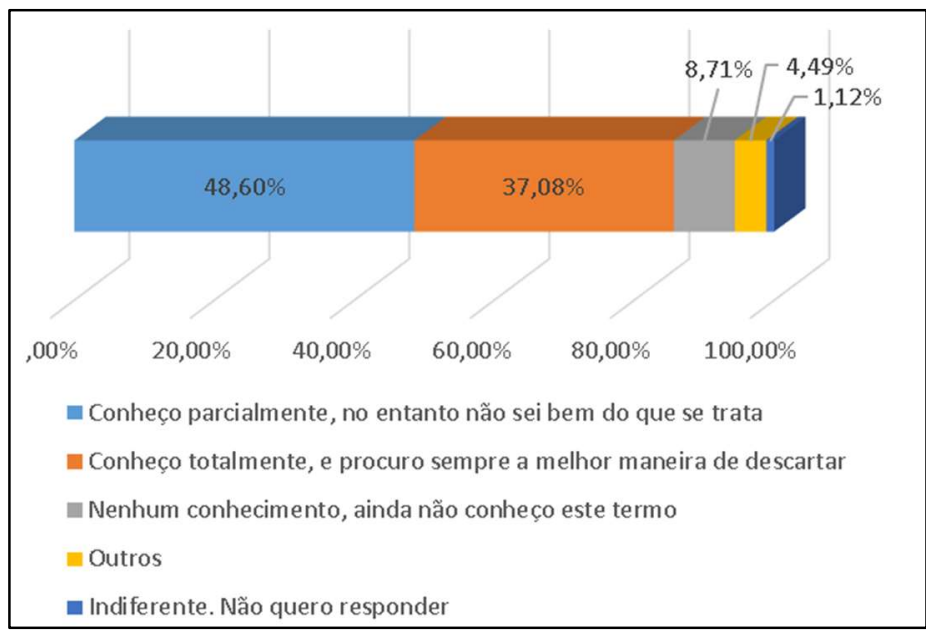

Gráfico 2: Nível de conhecimento dos respondentes sobre lixo eletrônico.

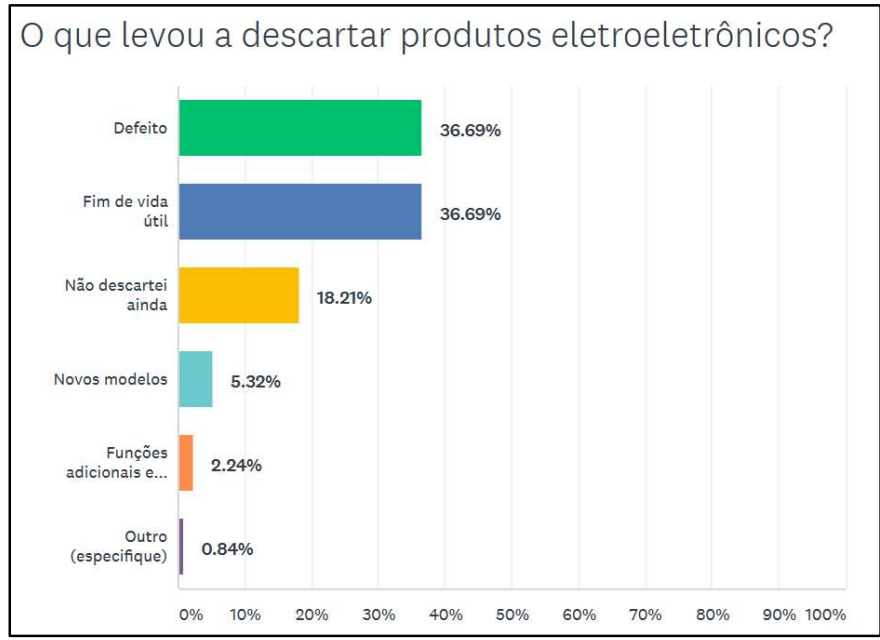

Gráfico 3: Motivos do descarte dos eletroeletrônicos.

De acordo com o gráfico 4, após a compra de um novo eletrônico, 40,28\% declararam realizar doação do antigo. Esta ação é importante porque o equipamento pode continuar em uso ou ter suas partes reaproveitadas. Corroborando com esse comportamento, tanto Maurer et al. (2012) como Maitino-Neto et al. (2012) afirmaram que a adoção de práticas de sustentabilidade associadas ao setor de Tecnologia da Informação permite reutilizar equipamentos, proporcionando uma vida útil maior aos computadores por meio de ações de recuperação das partes físicas, de seus componentes e periféricos.

Além da recuperação de equipamentos e sua reinserção em atividades, é preciso ficar atento à reciclagem de lixo eletrônico, pois o meio ambiente se tornou, se não a maior, uma das maiores preocupações das empresas e seus parceiros fornecedores (MAITINO-NETO et al., 2012). Uma alternativa que poderia ser disponibilizada a população seria o incentivo à doação de equipamentos eletrônicos, em bom estado de uso, para projetos sociais ou instituições do terceiro setor (XAVIER et al., 2019). Segundo Mansur (2011), dispositivos eletrônicos como celulares, computadores, impressoras e cartuchos podem se 
tornar em produtos de inclusão digital quando descartados.

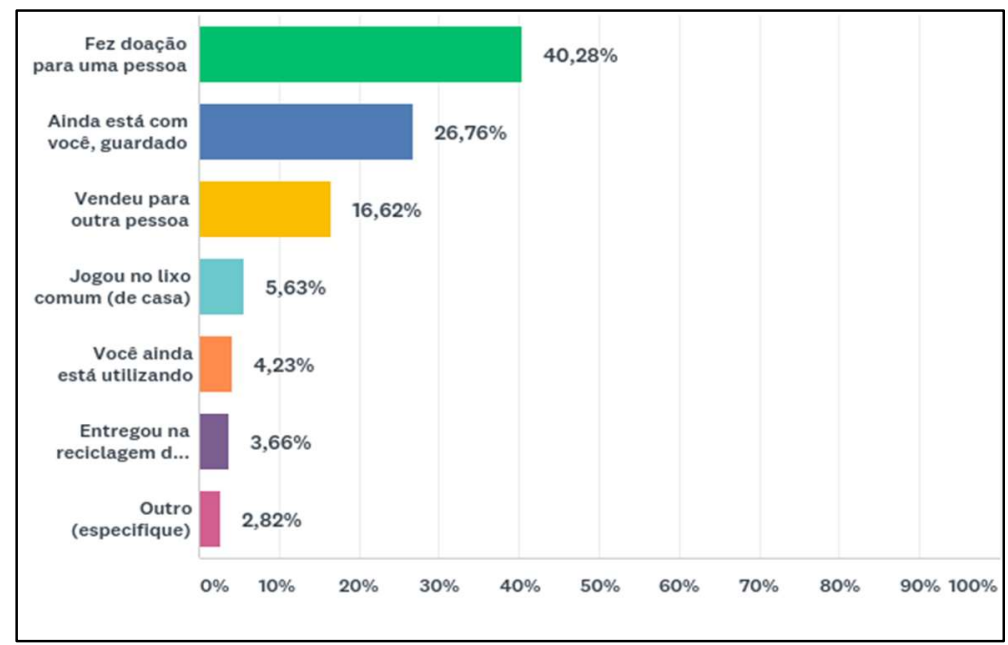

Gráfico 4: Forma de descarte dos eletroeletrônicos apontados pelos respondentes.

Quando inquiridos sobre se já tinham ouvido falar sobre pontos de coleta para descarte de eletroeletrônicos em Maceió/AL, 67,70\% negativaram suas respostas. Dado que sugere um mercado com forte possibilidade de expansão, pois existe a demanda, porém, não existe o serviço que venha a suprir as necessidades da população. Além do mais, pode apontar que as campanhas de sensibilização do poder público não estão sendo efetivas para divulgação desses locais de coleta.

Outro dado relevante, que pode ser visualizado no gráfico 5, é que apenas 5,34\% dos respondentes afirmaram que, ao adquirirem um novo equipamento, têm a preocupação de procurar no manual do produto informações acerca da questão ambiental, especialmente no que se refere à logística reversa, que envolve a responsabilidade do fabricante com o recolhimento e destinação dos REEs. Contrapondo com 49,16\%, que ao manusearem o manual, buscam apenas informações sobre como utilizar o equipamento.

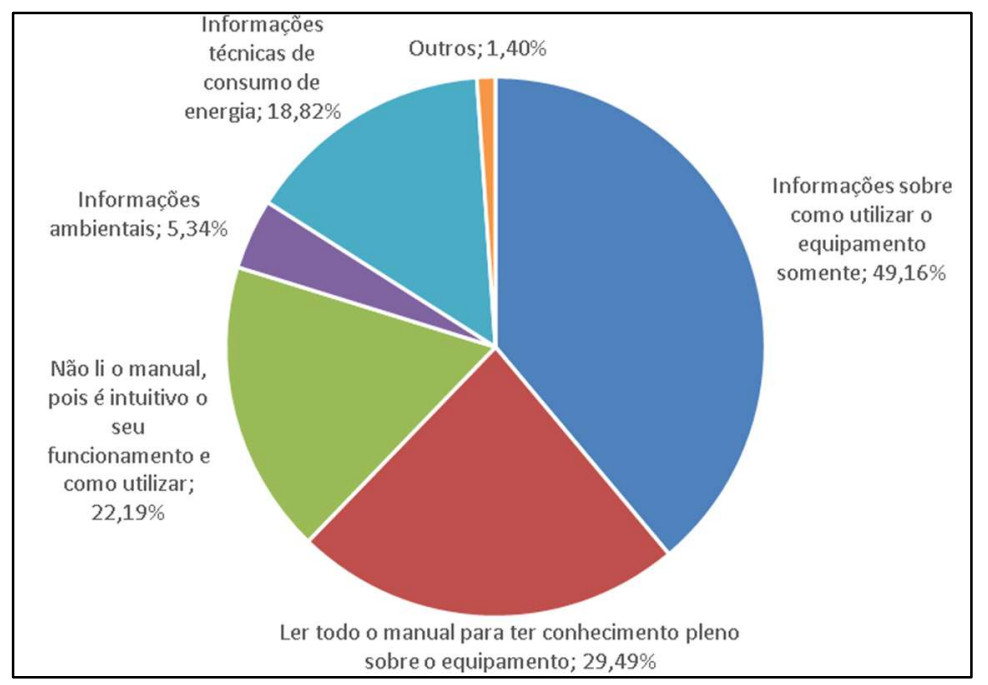

Gráfico 5: informações que os respondentes buscam no manual do produto.

Ao serem solicitados a apontar de quem é a responsabilidade pelo descarte de eletroeletrônicos (gráfico 6), 45,94\% dos entrevistados declararam que é da pessoa que o possui. Isso demonstra que as informações dispostas na PNRS, em relação à responsabilidade compartilhada, já estão, de certa forma, 
disseminadas entre a população. Dentre os respondentes, 15,69\% atribuíram ao município em que a pessoa reside a responsabilidade pelo recolhimento e destinação final ambientalmente correta, e apenas $12,32 \%$ sinalizaram o meio empresarial como agente partícipe na oferta de um programa de descarte responsável dos eletroeletrônicos.

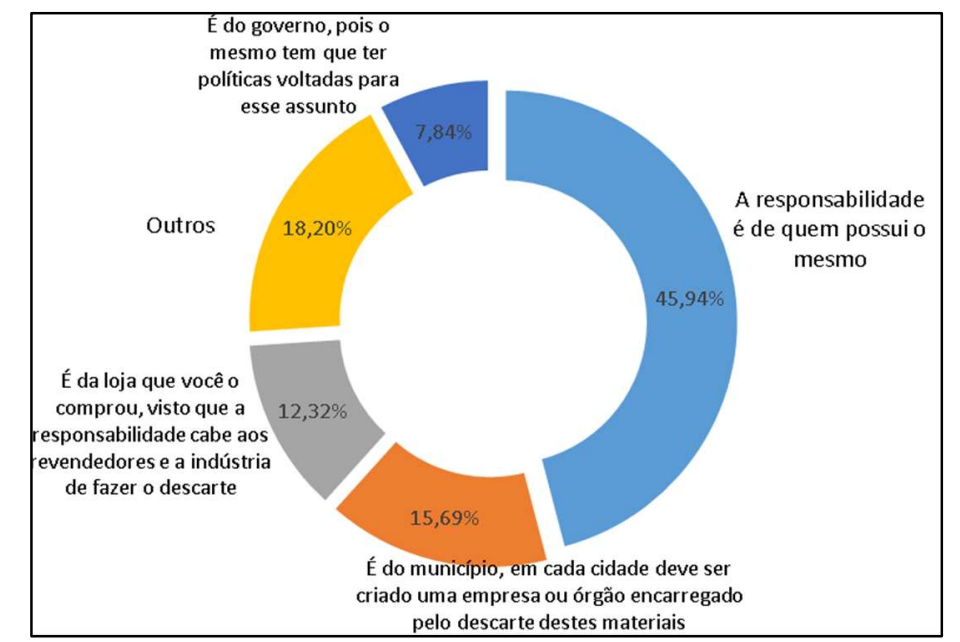

Gráfico 6: Sobre a responsabilidade do descarte dos eletroeletrônicos.

Etapa qualitativa: Confrontando a percepção da população com a atuação da empresa licenciada no município de Maceió/AL

A mensuração da percepção ambiental da população de Maceió/AL na etapa anterior da pesquisa acerca das atividades presentes na cadeia da logística reversa, especialmente naquelas que se referiram ao consumo, coleta e reciclagem de resíduos eletroeletrônicos, foi confrontada com a visão e atuação de uma empresa licenciada no município.

A empresa, que possui licença ambiental há sete anos, faz coleta das mais diversas categorias de eletroeletrônicos, desde os materiais da chamada "linha branca", como geladeiras, forno micro-ondas, máquina de lavar; além de computadores, monitores, pilhas e baterias inservíveis. Os itens recolhidos são devidamente descaracterizados, onde são separados os materiais de interesse comercial, conforme planejado pela gestão municipal (MACEIÓ, 2017).

No que concerne aos procedimentos relacionados ao descarte e respectiva destinação do resíduo eletroeletrônico, de acordo com o entrevistado, cada tipo de REEs tem seu 'custo específico de descarte, classificado nas categorias: ferro, vidro, pó de toner, pilha, plástico, placa eletrônica e bateria'. Sobre a destinação dos resíduos, o gestor afirmou que 'os mesmos são tratados em um procedimento de desmontagem por meio de separação magnética, em uma triagem para saber o tipo de material, sendo destinados para empresas parceiras dos estados de Pernambuco e São Paulo'. O gestor ainda explanou que 'entre os materiais mais tóxicos encontram-se os tubos de raios catódicos (CRT) e que os profissionais da empresa utilizam máscaras e luvas até a separação de todos os materiais, que são encaminhados para a destinação final'. Na entrada da empresa foi possível observar uma balança para realização de pesagem dos resíduos coletados e, caso seja necessário pesar um volume maior, é solicitado a pesagem avulsa. Infelizmente, confrontando essas informações com o que foi levantado na aplicação dos questionários, 
percebe-se que os detalhes inerentes ao processo de recepção e destinação dos resíduos ainda é desconhecido da maioria da população, que inclusive subestimam os níveis de toxicidade dos materiais que compõem os equipamentos eletrônicos descartados. Uma possibilidade de contornar esta situação é a empresa firmar mais parcerias com a academia para execução de projetos de extensão e de cunho social e ambiental junto aos alunos.

Por sua vez, no que se refere às campanhas de comunicação direcionadas à população, as mesmas são realizadas de forma direta pela empresa com postagens em folders, participação em eventos públicos ou privados, palestras e entrevistas nos meios de comunicação como rádio e televisão. A divulgação é feita distribuindo-se materiais impressos e também em redes sociais como o WhatsApp. São disponibilizadas, ainda, linhas telefônicas para recebimento de solicitações de coletas, 'sendo as mesmas agendadas e atendidas no menor tempo possível', conforme relatado. A empresa também incentiva a inclusão digital, investindo em máquinas para uma escola de informática, além de disponibilização de profissionais para palestras em eventos sem custo algum. Percebe-se aqui ações de divulgação relevantes, no entanto, confrontando com as respostas dos entrevistados, ainda incipiente em seu alcance. Devido ao fato de uma grande parcela da amostra pesquisada $(40,28 \%)$ ter declarado realizar doação do seu equipamento antigo, a empresa poderia se beneficiar disto para maximizar as oportunidades de reciclagem de equipamentos e então repassá-los para laboratórios de informática nas escolas ou associações sem fins lucrativos.

A empresa possui parcerias com órgãos públicos, entre eles: Superintendência de Limpeza Urbana de Maceió (SLUM), Instituto do Meio Ambiente de Alagoas (IMA) e Secretaria de Estado do Meio Ambiente e dos Recursos Hídricos (SEMARH). E existem 09 (nove) pontos de coleta distribuídos pela cidade. No entanto, a divulgação destes pontos ainda não tem sido eficaz, uma vez que quase $68 \%$ dos entrevistados afirmou desconhecer a existência dos mesmos.

'Os recursos utilizados pela empresa são 100\% próprios', afirmou o entrevistado, e continuou: 'esse recurso ainda é insuficiente para o atendimento da demanda', refletindo que falta suporte do poder público. Entretanto, as mudanças no mercado, segundo a empresa, vêm acontecendo, principalmente em relação a fiscalização, sugerindo que os órgãos reguladores estão mais atuantes, o que dificulta ações clandestinas e fortalece as empresas devidamente credenciadas e regularizadas, como é o caso da participante desta pesquisa.

Entre as dificuldades encontradas na operação da empresa, o entrevistado afirmou que há uma crescente demanda de coleta de REEs e que recebe solicitações de todo o estado e também de outros próximos. Uma demanda que sugere oportunidades para empreendedores investirem nesta área de coleta e destinação dos REEs.

Segundo o entrevistado, o 'grau de conscientização da população vem aumentando. Há um crescimento médio de 50 coletas/mês nas solicitações tanto de pessoas físicas quanto de jurídicas. Porém, existem casos de solicitações específicas com grandes volumes, podendo chegar em média $1000 \mathrm{~kg}$ por coleta'. Confrontando esta declaração com as respostas dos questionários, é possível perceber que as pessoas dizem conhecer o termo lixo eletrônico, mas ainda não apreenderam seu real significado e as ações 
sustentáveis do seu entorno, pois ficou evidenciado no questionário que um número considerável da população não costuma descartar o resíduo eletrônico, levantando a necessidade de divulgação e orientação acerca do seu manejo adequado.

\section{CONCLUSÕES}

A presente pesquisa tratou a problemática da logística reversa de resíduos eletroeletrônicos no município de Maceió/AL, sob os olhares de uma amostra da população e de uma empresa licenciada para manejo desse tipo de resíduo.

A etapa quantitativa da pesquisa descreveu um panorama geral do contexto de logística reversa de REEs em Maceió/AL no que tange às atividades presentes na cadeia, especialmente aquelas que se referem ao consumo, coleta e reciclagem de resíduos eletroeletrônicos. O aparelho celular foi o equipamento assinalado como o mais comprado $(91,27 \%)$ e, consequentemente, o mais descartado $(43,38 \%)$ pelos respondentes. Um número considerável de pessoas ainda não costuma descartar o resíduo eletrônico (32,68\%). 48,60\% dos respondentes alegaram conhecer parcialmente o termo lixo eletrônico, mas não sabem do que se trata. As principais motivações para o descarte dos produtos eletroeletrônicos foram 'defeito' e 'fim da vida útil', ambos com 36,69\%. Após a compra de um novo eletrônico, 40,28\% declararam realizar doação do antigo. 67,70\% afirmaram desconhecer a existência de pontos de coleta para descarte de resíduos eletroeletrônicos em Maceió/AL. Apenas 5,34\% dos respondentes afirmaram que, ao adquirir um novo equipamento, têm a preocupação de procurar no manual do produto informações acerca da questão ambiental. $45,94 \%$ dos entrevistados declararam entender que a responsabilidade pelo descarte correto dos REEs é do proprietário, o que demonstra, de certa forma, que as informações dispostas na PNRS, em relação à responsabilidade compartilhada.

Por sua vez, a etapa qualitativa da pesquisa envolveu entrevistas com o gestor de uma empresa que possui licença ambiental e foi pioneira na coleta e destinação de REEs em Maceió. Alguns insights são importantes destacar. A empresa realiza campanhas de comunicação ou sensibilização direcionadas à população, no entanto, foi possível perceber que ainda não tão efetivas. A empresa poderia se beneficiar do fato de uma boa parcela da amostra pesquisada $(40,28 \%)$ ter declarado realizar doação do seu equipamento antigo a fim de maximizar as oportunidades de captação de equipamentos para reciclagem. $\mathrm{O}$ gestor da empresa mencionou que há uma crescente demanda de coleta de REEs, que poderia atrair novos empreendedores para atuação neste nicho. Além disso, o grau de conscientização da população vem aumentando, na visão do gestor, pois a cada dia cresce o número de requisições e a quantidade de REEs para descarte.

Foi possível deduzir que a estrutura ainda incipiente da cadeia reversa de eletroeletrônicos no município propicia um cenário de descarte aleatório e inadequado, contrariando o determinado nos dispositivos legais vigentes no próprio município desde 2015. Inclusive, considerando a cadeia circular desses resíduos, há apenas duas empresas devidamente licenciadas pelos órgãos ambientais para manejo de REEs (uma delas foi a pesquisada), o que parece pouco para atender à crescente demanda da população. Foi 
possível notar que mesmo a empresa pesquisada se utilizando de toda uma propaganda nos meios governamentais e contando com nove pontos de coleta, ela ainda é praticamente invisível aos olhos da população.

Como sugestões para trabalhos futuros sobre a temática de REE, propõe-se analisar o mercado informal de lixo eletrônico no município de Maceió, caracterizando-o em um segmento paralelo à cadeia oficial da logística reversa, o que parece ser uma abordagem inovadora no entendimento deste fenômeno de cunho social e econômico. Outra proposta é aplicar modelos de simulação computacional, por exemplo a dinâmica de sistemas ou system dynamics (ZWICKER et al., 2019), para projetar e avaliar cenários a respeito da geração e descarte de REEs com o intuito de apoiar a gestão pública em políticas ambientais adequadas.

\section{REFERÊNCIAS}

ALAGOAS. Plano Estadual de Resíduos Sólidos do Estado de Alagoas. Maceió: SEMARH, 2016.

ARAÚJO, M. G.; MAGRINI, A.; MAHLER, C. F.; BILITEWSKI, B.. A model for estimation of potential generation of waste electrical and electronic equipment in Brazil. Waste Management, v.32, n.2, p.335-342, 2012. DOI: http://doi.org/10.1016/j.wasman.2011.09.020

BRASIL. Lei Federal n. 12.305, de 02 de agosto de 2010. Institui a Política Nacional de Resíduos Sólidos. Brasília: DOU, 2010.

CARDOZO, R. S.; MURAROLLI, P. L.. Tecnologia da Informação Verde: Sustentabilidade Tecnológica. O Avanço Da Tecnologia Em Relação Ao Meio Ambiente: Tecnologia E Sustentabilidade. Perspectivas em Ciências Tecnológicas, v.4, n.4, p.148-165, 2015.

COOPER, D. R.; SCHINDLER, P. S.. Métodos de Pesquisa em Administração. 7 ed. Porto Alegre: Bookman, 2003.

CRESWELL, J. W.. Research design: qualitative, quantitative, and mixed methods approaches. Califórnia: SAGE Publications, 2009.

DEMAJOROVIC, J.; AUGUSTO, E. E. F.; SOUZA; M. T. S.. Logística Reversa de REEE em Países em Desenvolvimento: Desafios e Perspectivas para o Modelo Brasileiro. Ambiente \& Sociedade, v.19, n.2, p.119-138, 2016. DOI: http://dx.doi.org/10.1590/1809-4422ASOC141545V1922016

DEMAJOROVIC, J.; MIGLIANO, J. E. B.. Política nacional de resíduos sólidos e suas implicações na cadeia da logística reversa de microcomputadores no Brasil. Gestão \& Regionalidade, v.29, n.87, p.64-80, 2013.

FRANCO, R. G. F.; LANGE L. C.. Estimativa do fluxo dos resíduos de equipamentos elétricos e eletrônicos no município de Belo Horizonte/MG, Brasil. Engenharia Sanitária e Ambiental, v.16, n.1, p.73-82, 2011.

FROTA, A. J. A.; TASSIGNY, M. M.; BIZARRIA, F. P. A.; BRASIL, M. V. O.; SILVA, I. M. G.. Coleta seletiva: perspectivas de sustentabilidade nas associações de catadores de resíduos sólidos na cidade de Fortaleza (CE). Revista Ibero-Americana de Ciências Ambientais, v.7, n.3, p.125-143, 2016. DOI: http://doi.org/10.6008/SPC2179-6858.2016.003.0011

GUNTHER, W. M. R.. Resíduos sólidos no contexto da saúde ambiental. Tese (Doutorado) - Universidade de São Paulo, São Paulo, 2008. DOI:

https://doi.org/10.11606/T.6.2010.tde-19072010-144112

LEEUW, E. D.; HOX, J. J.; DILLMAN, D. A.. International Handbook of Survey Methodology. Jena: The European Association of Methodology, 2008.

LEITE, P. R.. Logística Reversa: Meio Ambiente e Competitividade. 2 ed. São Paulo: Pearson Prentice Hall, 2009.

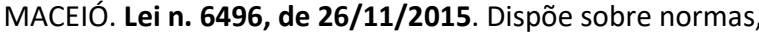
prazos e procedimentos para gerenciamento, coleta, reutilização, reciclagem e destinação final do lixo tecnológico. Maceió: DOM, 2015.

MACEIÓ. Plano Municipal de Gestão Integrada de Resíduos Sólidos do Município de Maceió/AL. Maceió: SEMPLA, 2017.

MACEIÓ. Lei n. 6933, de 04/09/2019. Institui o Código Municipal de Limpeza Urbana no Município de Maceió. Maceió: DOM, 2019.

MAITINO-NETO, R.; FAXINA, J. M.. TI Verde e Sustentabilidade. Revista de Ciências Exatas e Tecnologia, v.7, n.7, p.159-174, 2012

MANSUR, R.. Governança de TI verde: o ouro verde da nova TI. Rio de Janeiro: Ciência Moderna, 2011.

MAURER, E. B.; LANES, L. B. F.. Práticas sustentáveis em TI. Unoesc \& Ciência, v.3, n.2, p.187-194, 2012.

MOURA, A. C. V.; OLIVEIRA, N. M. R. M.; LOPES, M. C. M.; RAMOS, A. G.; BRITO, F. A.. Impactos socioambientais da atividade hoteleira na orla urbana de Maceió. Brazilian Applied Science Review, v.3, n.5, 2019.

NATUME, R. Y.; SANT'ANNA, F. S. P.. Resíduos Eletroeletrônicos: Um Desafio para o Desenvolvimento Sustentável e a Nova Lei da Política Nacional de Resíduos 
Sólidos. In: INTERNATIONAL WORKSHOP ADVANCES IN CLEANER PRODUCTION. Anais. São Paulo, 2011

OLIVEIRA, C. R.; BERNARDES, A. M.; GERBASE, A. E.. Collection and recycling of electronic scrap: A worldwide overview and comparison with the Brazilian situation. Waste Management, v.32, n.8, p.1592-1610, 2012.

RODRIGUES, A. C.. Fluxo domiciliar de geração e destinação de resíduos de equipamentos elétricos e eletrônicos no município de São Paulo/SP: caracterização e subsídios para políticas públicas. Tese (Doutorado em Saúde Ambiental) Universidade de São Paulo, São Paulo, 2012.

RODRIGUES, M. L.; MALHEIROS, T. F.; FERNANDES, V.; DAROS, T. D.. A percepção ambiental como instrumento de apoio na gestão e na formulação de políticas públicas ambientais. Saúde e Sociedade, v.21, n.3, p.96-110, 2012. DOI: http://doi.org/10.1590/S0104-12902012000700009

SACHUCK, M. I.; TAKAHASHI, L. Y.; AUGUSTO, C. A.. Impactos da inovação tecnológica na competitividade e nas relações de trabalho. Caderno de Administração, v.16, n.2, p.57-66, 2008.

SANT'ANNA, L. T.; MACHADO, R. T. M.; BRITO, M. J.. A logística reversa de resíduos eletroeletrônicos no Brasil e no mundo: o desafio da desarticulação dos atores.

Sustentabilidade em Debate, v.6, n.2, p.88-105, 2015. DOI: http://doi.org/10.18472/SustDeb.v6n2.2015.15522
SILVA, F. N.; CORREIA, J. L. L.; SILVA, E. C.; MARANGON, G. P.; PINTO, A. V. F.. Percepção Ambiental dos Alunos do Ensino Fundamental Il em uma das Escolas Públicas do Município de Maceió/AL. Revista Interdisciplinar Pensamento Científico, v.4, n.2, 2018.

SILVA, C. O.; KONRAD, O.; CALLADO, N. H.; ARAUJO, L. G. S.; HASAN, C.. Resíduos Sólidos Urbanos de Maceió/AL: Análise da Composição Gravimétrica sob Influências Sazonais. Revista Ibero-Americana de Ciências Ambientais, v.11, n. 3, 2020.

TIBBEN-LEMBKE, R. S.; ROGERS, D. S.. Diferences between forward and reverse logistics in a retail environment. Supply Chain Management: An International Journal, v.7, n.5, p.271-282, 2002. DOI: http://doi.org/10.1108/13598540210447719

XAVIER, L. H.; OTTONI, M.. Economia Circular e Mineração Urbana. Resíduos de Equipamentos Eletroeletrônicos. Rio de Janeiro: CETEM, 2019.

ZWICKER, A. M.; SCHNEIDER, J. R.; BELTRAME, G.; OLIVEIRA SIMONETTO, E.; LOBLER, M. L.. Simulação Baseada em System Dynamics para Avaliação de Cenários sobre Geração e Disposição de Resíduos Eletrônicos em uma Instituição de Ensino Superior. Desenvolvimento em Questão, v.17, n.47, 2019. DOI: http://doi.org/10.21527/2237-6453.2019.47.357$\underline{372}$

A CBPC - Companhia Brasileira de Produção Científica (CNPJ: 11.221.422/0001-03) detém os direitos materiais desta publicação. Os direitos referem-se à publicação do trabalho em qualquer parte do mundo, incluindo os direitos às renovações, expansões e disseminações da contribuição, bem como outros direitos subsidiários. Todos os trabalhos publicados eletronicamente poderão posteriormente ser publicados em coletâneas impressas sob coordenação da Sustenere Publishing, da Companhia Brasileira de Produção Científica e seus parceiros autorizados. Os (as) autores (as) preservam os direitos autorais, mas não têm permissão para a publicação da contribuição em outro meio, impresso ou digital, em português ou em tradução. 